\title{
NOTE ON TRANSCRIPTION
}

\section{AND TERMINOLOGY}

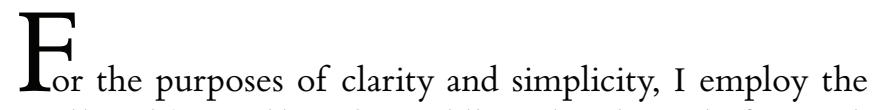

Arabic letters ayn ( $\left.{ }^{\circ}\right)$ and hamza (') in the middle and at the end of a word, but not at the beginning, and, for the most part, the common French spelling of Arabic names and places (e.g., Kabylie, not Kabylia; Mohamed, not Muhammad). With some reluctance, I also employ the commonly written "Hassan" for what are two distinct names in Arabic, "Hasan" and "Hassan." As for the use of "Berber" and "Amazigh," the reader will see that there are times when it was appropriate to use one, as opposed to the other, and that at other times, I use them interchangeably, without prejudice. 
THIS PAGE INTENTIONALLY LEFT BLANK 